\title{
Linguagem e documento: fundamentos evolutivos e culturais da Ciência da Informação
}

\section{Carlos Henrique Marcondes}

\begin{abstract}
Doutor em Ciência da Informação, pesquisador do CNPq, professor do Departamento de Ciência da Informação e Programa de Pós-graduação em Ciência da Informação, UFF
\end{abstract}

São propostas bases antropológicas, evolutivas, culturais e sociais como fundamentos para a Ciência da Informação, a partir de uma discussão sobre o papel central desempenhado pela linguagem no desenvolvimento da cultura e na configuração das sociedades humanas. É discutido seu papel como mecanismo de cooperação e articulação social, que garante à espécie humana um diferencial evolutivo decisivo. Este papel da linguagem é mantido e ampliado através da invenção do documento, em sociedades humanas cada vez mais complexas. O documento é analisado em diferentes perspectivas e são discutidas suas possíveis relações com a Ciência da Informação.

Palavras-chave: Ciência da Informação; Fundamentos; Cultura; Documento.

\section{Language and Document: evolutionary and cultural foundations of Information Science}

Anthropological, evolutionary, cultural and social bases are proposed as the foundation for Information Science. The proposition starts from a perspective which discusses the central role of language in the development of culture and shaping of human societies. The role of language as a social coordination and cooperation mechanism which provide mankind with an evolutionary differential is discussed. This essential role of language is maintained and amplified through invention of the document in evermore complex human societies. The document is 
analyzed under different perspectives and its possible relations to Information Science are discussed.

Keywords: Information Science; Foundations; Culture; Document.

Recebido em 04.02.2010 Aceito em 30.06.2010

\section{Introdução}

Informação é um fenômeno de ampla abrangência, a ponto de ser mesmo identificado como uma das entidades fundamentais da realidade, junto com a matéria e energia (MAARTENS, 2007). É também de interesse de diversas áreas de conhecimento, desde a Biologia, Matemática, Computação, Comunicação, Psicologia, Educação, Administração, etc. Além disso, na atualidade, a mídia, sempre em busca de novidades, valoriza ao extremo o fato de estarmos vivendo na assim chamada "Sociedade da Informação", mitificando-a e associando-a tão somente à emergência e à disponibilidade dos mais recentes "gadgets", disponibilizados pelas indústrias de TI. Informação é assim, um conceito que vem sendo banalizado, que serve para designar muitas coisas e nada ao mesmo tempo, sendo utilizado de maneira tão livre e intuitiva em procedimentos administrativos, em nosso dia-a-dia e mesmo em diversas áreas científicas, que tem resultado numa grande confusão para um uso científico do conceito.

A área de conhecimento da Ciência da Informação tem se ressentido desses problemas. Seu uso coloquial e a falta de rigor definitório e conceitual consensual tem inclusive contaminado muito do discurso que se reivindica da Ciência da Informação. Definições iniciais da área como as cunhadas no evento considerado fundador da disciplina, no Geórgia Institute of Technology, no início da década de 1960 do século XX, são pouco rigorosas e muitas vezes praticamente circulares, uma vez que não definem o que seja informação. Ciência da Informação seria, portanto: "Ciência que investiga as propriedades e comportamento da informação, as forças que governam o fluxo de informação e os meios de processamento da informação para otimização da acessibilidade e do uso" ${ }^{11}$ (SHERA; CLEVELAND, 1997, p. 265).

Pioneiros da Ciência da Informação, na década de 1960, a conceituavam como uma disciplina voltada para problemas, em especial o assim chamado problema da "explosão informacional", que caracterizaria a sociedade que se delineava no pós $2^{\mathrm{a}}$. Guerra Mundial, em oposição às sociedades anteriores.

\footnotetext{
${ }^{1}$ Tradução nossa.
} 
Essa ênfase operacional da Ciência da Informação em seus primórdios, se por um lado deixou lacunas e contribuiu para uma grande confusão conceitual da qual a Ciência da Informação se ressente até hoje, pelo lado econômico da assim chamada "indústria da informação" se constituiu num sucesso, dando origem a um dos setores econômicos mais dinâmicos da sociedade atual. Esse forte setor econômico da "indústria da informação" contribuiu pelo seu peso social, pelas suas ligações com a mídia, pelos fortes interesses econômicos mobilizados, para cristalizar conceitos e terminologias para o fenômeno informação - num processo chamado por Freitas (2003) de "invenção da informação" - destituídos do necessário rigor requerido por uma disciplina científica.

A principal confusão introduzida pelo uso coloquial e a-científico do termo pela mídia é denominar informação tanto toda a parafernália de registros ou objetos com potencial informativo disponíveis nas redes eletrônicas na sociedade atual quanto o processo humano de informar ou informar-se propriamente dito. Diz-se que registros com potencial informativo, como os existentes numa base de dados na Web ou disponíveis através de um mecanismo de busca como o Google, são "informação".

A maneira de lidar com essa situação talvez seja, sem esquecer a riqueza e o potencial dados pela generalidade e transversalidade do conceito por diversas áreas de conhecimento e procurando manter para a Ciência da Informação uma compatibilidade com este escopo mais abrangente, procurar delimitar claramente um conceito de informação de interesse da Ciência da Informação. Isso vem sendo feito por vários autores ao longo da discussão epistemológica da Ciência da Informação.

Autores têm buscado, acertadamente, bases conceituais para a área a partir de uma definição de informação (BELKIN; ROBERTSON, 1976; BUCKLAND, 1991; BATES, 2005). O recente artigo de Zins (2006) coloca, no entanto, para a Ciência da Informação uma situação desanimadora. A multiplicidade de formulações para conceitos fundamentais para a área como dados, informação e conhecimento se torna um sério obstáculo para o ensino, a pesquisa e o planejamento/gestão de sistemas de informação. A par de continuar na busca de delimitação do escopo e abrangência da Ciência da Informação, um movimento que buscasse bases outras que as simplesmente orientadas a problemas, como tem sido uma prática comum, ou então epistemológicas - lógicas, definitórias ou classificatórias - bases que pudessem alcançar um grau maior de consenso, poderia contribuir para dar maior consistência e fundamentar a Ciência da Informação.

Nenhum pesquisador sério, hoje, questionaria a Teoria da Evolução de Darwin ou a Teoria da Relatividade de Einstein. As evidências da validade dessas teorias têm se acumulado desde as suas formulações. Grandes consensos científicos podem fornecer bases mais sólidas para a Ciência da Informação. O objetivo deste trabalho é, portanto, buscar e propor bases antropológicas, evolutivas, sociais e culturais como fundamentos para a Ciência da Informação. Recentes descobertas da Psicologia Evolutiva, da Antropologia Social, da Biologia Evolutiva, 
principalmente, têm iluminado questões relativas à evolução humana e o papel nesta do social, da cultura e da linguagem, nela. Se conseguirmos seguir uma linha evolutiva pelas questões colocadas por essas disciplinas até encontrarmos os atores, objetos, processos e relações de interesse para a Ciência da Informação, teremos contribuído para alicerçar nossa disciplina em bases mais sólidas e com mais potencial de consenso.

Apesar de reconhecimentos esparsos ao longo da sua história do débito da Ciência da Informação com a Documentação, a discussão do documento dentro da CI foi, de certa forma, ofuscada e mesmo considerada ultrapassada frente a um objeto que parece ter um apelo muito maior, a informação (FREITAS, 2003). A recente revalorização das discussões sobre o documento na CI - Lund (2009, p. 399) fala de "a renaissance for the document approach" - mostra como muita elaboração teórica ainda é necessária para compatibilizar e integrar a questão do documento no escopo teórico da CI. É necessário avançar na construção de uma consistente teoria do documento, incluindo aí sua relação com a "informação", uma ontologia do documento, não somente no sentido do que ele é hoje, mas dos processos históricos que o permitiram ele vir a ser o que é uma teoria que abranja seus usos sociais.

A tese aqui proposta é que mecanismos para enfrentar a chamada "explosão informacional" que caracterizaria a sociedade atual, aparentemente um fenômeno tão contemporâneo, tem raízes nos mecanismos de articulação social que remontam às sociedades humanas mais primitivas. A evolução histórica da sociedade humana para formas cada vez mais complexas, ao ser um imperativo evolutivo e de sobrevivência da própria espécie humana, demanda pari passo mecanismos de articulação sociais cada vez mais complexos, que são providos num primeiro momento pela linguagem e, posteriormente, por documentos.

A metodologia utilizada foi a análise retrospectiva a partir de textos recentes de Antropologia Cultural, Biologia Evolutiva e Psicologia Evolutiva onde são discutidos aspectos antropológicos e evolutivos da humanidade e do papel da linguagem e cultura nestes processos. Autores como Tattersall (2007), discutindo o surgimento da cognição moderna, Nowak e Komarova (2001), discutindo o surgimento da linguagem, Dunbar (1993) e Knight et al. (2000), discutindo o papel social da linguagem, Maturana e Varela (2000), discutindo os fundamentos biológicos da cognição humana, lançam novas luzes para compreensão do papel dessas questões na evolução humana. Também aportes de teorias meta-disciplinares como a Teoria Geral dos Sistemas e a Semiótica são buscadas para a compreensão dos processos informativos. Dessas discussões também emerge a noção de articulação e cooperação social, essencial para a linha de argumentação aqui desenvolvida. Cognição, cultura e linguagem são noções fundamentais para uma discussão sobre os fundamentos da CI. A partir dessas visões são percorridas questões como a emergência do pensamento simbólico, o surgimento da cultura, da linguagem, da escrita, para culminar no documento. A partir dessa visão evolutiva, o documento é então analisado segundo perspectivas funcionais, sociais e culturais. 


\section{Evolução humana, linguagem e cultura}

O que quer que seja que nós possamos afirmar, cada um de nós tem uma visão subjetiva daqueles aspectos do mundo e de suas questões que relaciona-se com nossos interesses. Na medida em que cada visão subjetiva pode diferir de outras, o convívio social amigável requer de nós que reduzamos os riscos de desacordos estabelecendo padrões, acordos e regulamentações socialmente consensados [...] para a condução da vida em comum. Este contínuo esforço social de corrigir os erros que a nossa subjetividade nos conduz é o que chamo de objetivação (BROOKES, 1980 , p. 209).

O homem, enquanto ser biológico, seguindo uma trajetória que remonta aos grandes antropóides, tem sua sobrevivência individual e sua evolução enquanto espécie, irremediavelmente ligadas a sua organização social. Maturana e Varela (2001, p. 217) chamam de fenômenos sociais "a participação de organismos na constituição de unidades de terceira ordem". Para os autores, unidades de terceira ordem seriam agrupamentos sociais formados pela articulação de indivíduos, organismos multicelulares dotados de sistema nervoso (unidades de segunda ordem). Esta participação tem um caráter específico e fundamental para a vida desses organismos: "[...] os organismos participantes satisfazem suas ontogenias individuais principalmente pelo acoplamento mútuo, na rede de interações recíprocas que formam ao constituir as unidades de terceira ordem" (MATURANA; VARELA, 2001, p. 217). Em outras palavras, a vida social, em algumas espécies, torna-se essencial para a sobrevivência de cada indivíduo.

No homem, mais que em qualquer outra espécie, o social tem um peso evolutivo decisivo. Mais do que buscar causas ou sequências que a própria Antropologia não consegue estabelecer com precisão, observa-se na espécie humana características que foram se firmando ao longo da evolução, que vinculam esta evolução ao social. O homem não é excepcionalmente forte ou rápido em comparação aos predadores e a caça; macho e fêmea são unidos por uma sexualidade permanente e não sazonal; a maturação do bebê humano é lenta quando comparada a outras espécies; pai e mãe e o restante do grupo têm que colaborar na busca de alimento, na criação e proteção dos filhos; a postura bípede que se firmou na espécie humana permitia mãos livres para carregar alimento até o grupo, desobrigando o homem de levá-lo imediatamente à boca. A alimentação, que passava a incluir crescentemente carne, permitiu um aumento do volume cerebral.

\footnotetext{
${ }^{2}$ Tradução nossa.
} 
Este conjunto de características vai se firmando ao longo da evolução humana de tal forma que o social passa a adquirir um caráter estrutural. De um ponto de vista evolutivo, dentro dos mecanismos de interação social humanos, certamente a linguagem (VYGOTKKY, 2001) tem um caráter determinante. Nowak e Komarova (2001, p. 288) destacam este aspecto:

A linguagem permitiu aos nossos ancestrais compartilhar idéias e experiências e resolver vários problemas simultaneamente. O significado adaptativo da linguagem humana é óbvio. É vantajoso falar. Cooperação nas caçadas, coordenação de atividades, compartilhamento de tarefas, manutenção de vínculos sociais, manipulações e trapaças, todas estas atividades se beneficiam de uma crescente poder expressivo da linguagem. A seleção natural (incluindo a seleção sexual) pode certamente demonstrar conseqüências da comunicação ${ }^{3}$.

Do ponto de vista funcional-genético, as habilidades linguísticas dependem de um gene denominado FOXP2 (ENARD et al., 2002). Estes autores apresentam um estudo comparado do FOXP2 em macacos, antropóides e no homem. As habilidades linguísticas humanas envolvem um controle sofisticado de órgãos como a laringe e a boca, que são viabilizadas por este gene, não estão presentes no chimpanzé. Os estudos de Enard apontam que esta característica fixou-se na espécie humana há cerca de 100.000 anos, o que é compatível com as descobertas relatadas por Wong (2007) relativas a vestígios da emergência do pensamento simbólico na forma de adornos e desenhos em objetos de pedra, datados de período semelhantes e encontrados num sítio arqueológico da África do Sul.

Animais em geral e antropóides em especial comunicam-se para articularem seus comportamentos individuais. Para isso, utilizam diferentes sinais, gestos e sons. Karl Bühler (1990, p. 34) vê na linguagem humana um sistema de comunicação entre indivíduos e identifica nela três funções semânticas: expressiva, apelativa e descritiva. Algo semelhante à função apelativa de Bühler pode ser encontrada em diferentes animais. Karl Popper (1997) afirma que as duas primeiras dessas funções são características também dos animais, conforme exemplifica Vygotsky (2001, p. 9), ao discutir as especificidades da linguagem humana em relação aos sistemas comunicativos dos animais: "O ganso atemorizado que de súbito se apercebe dum perigo e alerta todo o bando com os seus gritos não está dizendo aos restantes o que viu, antes está contaminando os outros com o seu medo".

Às funções propostas por Bühler, Popper (1997) acrescenta-se uma quarta, a argumentativa, fundamental para a discussão da linguagem enquanto um instrumento de transferência de conhecimento.

\footnotetext{
${ }^{3}$ Tradução nossa.
} 
Nenhum sistema de comunicação encontrado no reino animal se compara, no entanto, à linguagem humana, às funções simbólicas que são características da linguagem humana. Várias teorias atribuem a origem da linguagem humana à existência de uma protolinguagem (NOWAK; KOMARONOVA, 2001). A partir de sons isolados - palavras - associados a significados numa relação um para um, a linguagem humana evoluiu, incorporando funções sintáticas (CHOMSKY, 2002), a serialização de palavras (NOWAK; KOMARONOVA, 2001). Na linguagem humana significados não são somente dados por palavras isoladas, mas por combinações de palavras. Dessa forma, podiam ser criadas possibilidades infinitas de combinações e, consequentemente, de novos significados. Estes autores mostram como esta crescente flexibilização junto com ao potencial comunicativo e a economia de energia proporcionada pela linguagem humana acabaram tornando-a um diferencial evolutivo decisivo.

A linguagem, como um primeiro grau de externalização do pensamento simbólico, permite maior cooperação e articulação social. Dunbar (1993) ao discutir a vida social dos primatas chama atenção para o tempo gasto nos contatos sociais necessários para manter a estabilidade e os vínculos do grupo: macacos passam grande parte do seu tempo coçando uns aos outros ou catando piolhos. Ao discutir os contatos sociais em grupos de humanos primitivos, esse autor afirma que a possibilidade de grupos sociais maiores dependia de mecanismos mais eficientes de manter os contatos sociais indispensáveis à coesão do grupo e afirma que só a linguagem cumpria esta finalidade.

Com certeza, uma mutação genética por si só não criou a linguagem, mas esta habilidade encontrou nos grupos sociais humanos cada vez mais complexos a possibilidade de desenvolver-se. As mutações que viabilizaram a linguagem humana foram as últimas alterações biológicas significativas na espécie humana. Somos hoje biologicamente idênticos aos nossos antepassados de 100.000 anos atrás. A partir deste período o grande vetor evolutivo da humanidade tem sido a cultura.

A linguagem é uma característica humana que é pré-requisito para a evolução da cultura como nós a entendemos, uma cultura crescentemente acumulativa. Uma linguagem cada vez mais sofisticada no sentido de ser capaz de expressar pensamento simbólico, ou seja, capaz de contar, descrever, re-apresentar, socializar situações na ausência delas, argumentar, convencer, se torna um forte mecanismo de cooperação e articulação social e garante à espécie humana um diferencial evolutivo decisivo.

Num momento histórico mais recente, há cerca de 5.000 anos A.C., no contexto já de sociedades humanas bastante complexas, a linguagem falada é externalizada, fixada, tem superada sua fragilidade e perenidade como mecanismo de comunicação intersubjetivo, materializada através de artefatos na escrita e, dessa, no documento.

\section{Documento}


Tu, como pai da escrita, esperas dela com teu entusiasmo precisamente o contrário do que ela pode fazer. Tal coisa tornará os homens esquecidos, pois deixarão de cultivar a memória; confiando apenas nos livros escritos, só se lembrarão de um assunto exteriormente e por meio de sinais, e não em si mesmos. Logo, tu não inventaste um auxiliar para a memória, mas apenas para a recordação (PLATÃO, 2007, p. 119).

E ainda:

[...] os discursos. Falam das coisas como se as conhecessem, mas quando alguém quer interrogar-se sobre qualquer assunto exposto, eles se limitam a repetir sempre a mesma coisa. Uma vez escrito, um discurso sai a vagar por toda a parte, não só entre os conhecedores, mas também entre os que o não entendem, e nunca se pode dizer para quem serve e para quem não serve. Quando é desprezado ou injustamente censurado, necessita do pai, pois não é capaz de defender-se nem de se proteger por si (PLATÃO, 2007, p. 120).

As palavras de Sócrates no Diálogo Fedro, de Platão (2007), são uma alegoria da passagem de uma cultura com base na oralidade e na memória para uma baseada na escrita, e das perdas daí decorrentes. No entanto, a autonomia dos registros de conhecimento com relação ao seu autor/formulador dada pela escrita e as múltiplas possibilidades abertas para a cultura humana, tornam-se um processo historicamente irreversível. Essa autonomia é reconhecida por Popper (1992), quando classifica a realidade em três mundos: o mundo físico ou Mundo 1; 0 mundo psíquico ou Mundo 2; e o mundo dos produtos intelectuais ou Mundo 3. A classificação de Popper é a base para a proposta de Brookes (1980) do Mundo 3, o dos objetos culturais, naturalmente externalizados, como a área de atuação da CI.

Pode-se considerar as estelas de pedra, como a Estela dos Abutres (ARTE NOS SÉCULOS, s. d.), encontrados na Mesopotâmia, como um dos primeiros monumentos da história humana. Quando relacionados com a escrita, o surgimento de estelas votivas, relatando os feitos guerreiros de reis como as encontradas na Mesopotâmia e Egito, é mais ou menos contemporâneo ao surgimento das primeiras tábuas de barro com a escrita cuneiforme e dos primeiros papiros com hieróglifos. Le Goff (2003) faz uma distinção entre monumento e documento. Ambos pretendem perenizar uma mensagem. No entanto, a diferença é que o documento, ao contrário do monumento, era e é hoje cada vez mais portátil e autônomo em relação à presença do seu criador. Ao contrário do monumento, imóvel, o documento permite fixar uma mensagem e transferi-la não somente através do tempo, como o monumento, mas também (e cada vez mais) através do espaço. O documento, portanto, é um artefato sóciotécnico, artificial, uma descoberta tecnológica, correlata à descoberta da 
escrita, que permite viabilizar a intenção de seu criador de transferir mensagens, externalizadas e autonomizadas, através do tempo e do espaço. Externalização e autonomia significam também, necessariamente, registro num meio físico, criando assim um objeto sócio-técnico, com todas as consequências daí decorrentes.

Se para Sócrates, no Fedro, a escrita traria inconvenientes tão sérios para a memória e o conhecimento, esta descoberta tecnológica, que provavelmente não tem um criador único, abriu para a humanidade um enorme potencial de desenvolvimento social/cultural (apesar das restrições de Sócrates, no Fedro). Sociedades social e culturalmente cada vez mais complexas puderam se articular, cooperar, garantir a preservação da cultura e do conhecimento duramente adquirido pelas gerações anteriores, mediados por documentos. Neste sentido o documento guarda uma continuidade evolutiva e amplia as potencialidades da cultura e da linguagem.

Documentos têm, primariamente, um caráter instrumental. As mensagens transferidas através de documentos têm a intenção genérica de informarem algo, ou seja, de alterarem o quadro mental de possíveis receptores, como postula Belkin (1976), um dos primeiros pensadores da Ciência da Informação que teorizaram sobre o conceito de informação. Por meio de sua função informativa, documentos viabilizam, de forma mediada, a transferência de conhecimento, como é comumente discutido no contexto da Ciência da Informação. Em seu início, a Ciência da Informação, ao endereçar o problema de gerir grandes massas documentais em C\&T, supervalorizava o aspecto de seus conteúdos, a chamada "informação", praticamente caminhando na direção de uma autonomia dessa em relação ao documento, aos seus aspectos físicos e ao seu contexto. Esta visão, levada às últimas consequências, levaria aos sistemas de pergunta e resposta, aos sistemas especialistas, aos mecanismos de aquisição de conhecimento de peritos humanos, à sua formalização como regras e seu re-uso e combinação nos mais variados contextos.

Embora isto possa ter alguma validade em contextos específicos como a Ciência, com sua proposta de conhecimento com validade universal, é uma visão por demais unilateral para servir de base a uma teoria geral do uso social da "informação". A ênfase no conteúdo como insumo de processos interpretativos levou a Ciência da Informação à reificação da informação enquanto uma a essência autônoma (FROHMANN, 1995). Esta noção de informação, centrada em seu conteúdo, não dá conta, porém, de outras perspectivas, decorrentes da natureza do documento enquanto artefato sócio-técnico, da sua autonomia, externalização e registro.

Como consequência e desdobramento de sua função informativa, que se dá em contextos sociais muito específicos, documentos têm uma função social-simbólica, normativa, como é colocado por Briet (2006, p. 9) "a Document is a proof in support of a fact". Documentos vêm sendo cada vez mais vistos (BROWN; DUGUID, 1996; SMITH, 2005; FROHMANN, 2006) como instrumentos instaurados e instauradores de protocolos e 
relações sociais. Uma infinidade de relações sociais essenciais para o funcionamento de sociedades cada vez mais complexas ${ }^{4}$, regidas por relações normativas em oposição às relações pessoais, características das sociedades mais primitivas, são mediadas por documentos. Barry Smith (2005) faz alusão ao texto de John Searle intitulado "Speech Acts" quando propõe uma teoria que o autor chama de "document acts": "[...] it might be used to provide a better understanding of the role of documents in the coordination of human actions". Estas funções do documento, de articulação, coordenação e cooperação social, se aplicam também, naturalmente, à sociedade contemporânea. Nessa perspectiva, o uso de documentos carrega uma série de pressupostos ontológicos nem sempre explicitados, mas fundamentais para a compreensão do seu papel, na forma de protocolos sociais como normas, acordos, legislação, mecanismos de coerção social, diferentes atores, tecnologias, etc.

Documentos também devem ser considerados como condicionados tecnologicamente. Evoluíram das tabuinhas de barro e dos papiros para os pergaminhos de pele, para os códices, para os documentos impressos até os documentos digitais da atualidade. Muita coisa mudou nesta evolução, mas, também, muita coisa permanece. Discussões sobre a desmaterialização trazida pelos documentos digitais fazem pouco sentido ou só têm sentido quando discutidas teoricamente. Documentos são unidades discretas de registro e transferência de mensagens; a aparente fluidez de limites dos documentos digitais hipertextuais, problemas de validade desses documentos, são decorrência do estágio tecnológico recente de desenvolvimento dos documentos digitais que logo serão superados pelo desenvolvimento tecnológico. Um usuário concreto conhece muito bem as fronteiras dos documentos que usa. Devemos nos lembrar que estamos numa fase de transição entre uma sociedade que utiliza documentos em papel para uma que utiliza documentos digitais.

Documentos também têm um ciclo de vida, como já foi reconhecido há tempos pela Arquivística (ROUSSEU; COUTURE, 1998). Ao cumprirem sua função primária de informarem e regularem relações sociais, documentos podem vir a adquirir um caráter secundário, ao serem identificados como tendo valor de patrimônios culturais.

A questão da intencionalidade também é uma característica dos documentos, que são, como já colocado, artefatos artificiais, criados com a intenção de informar.

Este ponto também é essencial, já que, desde os tempos de Suzanne Briet (BUCKLAND, 1991), nossa área discute o caráter documental de objetos, como o antílope de Briet, colocado numa coleção zoológica. No texto citado Buckland chega a conclusão que qualquer coisa pode ser informativa: "If anything is, or might be, informative, then everything is, or might well be, information".

\footnotetext{
${ }^{4}$ A Teoria Geral dos Sistemas considera as sociedades humanas como um dos exemplos de sistemas complexos. Ver Santaella (2008).

${ }^{5}$ SEARLE, J. R. Speech acts: an essay in the philosophy of language. Cambridge: Cambridge University Press, 1969.
} 
Noções como informação (em termos abstratos), objeto informativo, ou objeto com potencial de informar, são, portanto, mais amplas que a de documento. Qualquer coisa, como coloca Buckland, pode ser informativa, a natureza em geral pode ser informativa, é plena de potencial informativo. A chave para compreendermos os processos informativos é dada pela Semiótica (Santaella, 2008). Vários autores (RABER; BUDD, 2003; BRIER, 2004; HUANG, 2006) têm buscado aportes da Semiótica para chegarem às definições de informação. O criador da Semiótica moderna, Charles Sanders Pierce (1958), citado por Santaella (2008, p. 62) afirma que:

O signo é qualquer coisa que é de um lado, de tal modo é determinado por um objeto e, por outro lado, de tal modo determina uma idéia na mente de alguém que esta última determinação, chamada de interpretante do signo, é conseqüentemente determinada mediatamente por aquele objeto.

Um documento é, portanto, muito mais que somente um "portador de informações", limitado ao seu conteúdo intrínseco e à sua interpretação por um usuário, como colocado em algumas visões iniciais da CI, aplicadas a contextos de transferência de textos científicos. Apesar da Semiótica trazer para a discussão da informação a questão da interpretação, que normalmente está associada a processos subjetivos, este grau de subjetividade dos processos interpretativos deve ser relativizado quando a linguagem humana é usada para comunicar mensagens, função para a qual ela tem sido extremamente efetiva. Quando nos primórdios da cultura humana nossos antepassados falavam de "comida", "perigo", "atração sexual", estas mensagens eram muito claras.

Isolar formas, conteúdos e contextos sociais de produção e uso de documentos traz prejuízos para a interpretação desses conteúdos. A evolução das sociedades humanas mostra que os processos comunicativos que fazem uso da linguagem, aí inclusos documentos, apesar de terem aspectos de subjetividade, quando vistos em seus contextos sociais de uso específicos, são bastante precisos quanto ao seu significado. O significado não esta no documento em si, mas sim no documento dentro de contextos específicos. É isso que permite que documentos funcionem como mecanismos de articulação, coordenação e cooperação social. A linguagem como mecanismo primordial neste sentido, só pode dar conta desse papel em sociedades cada vez maiores e mais complexas quando externalizada através de artefatos sócio-técnicos como documentos. As funções da linguagem (BÜHLER, 1990; POPPER, 1997) foram herdadas e ampliadas nos documentos.

Assim, qualquer coisa, objetos ou fenômenos, é informação, ou melhor, é informativa, quando está inserida numa relação sígnica com um intérprete. A etimologia da palavra informação é bastante esclarecedora 
sobre seu significado. Segundo o Online Etymology Dictionary informação quer dizer: "1387, 'act of informing', from O.Fr. informacion, from $L$. informationem (nom. informatio) 'outline, concept, idea', noun of action from informare". Assim, informação, no contexto que possa interessar à Ciência da Informação, não é uma coisa, é um processo, o processo de interpretar fenômenos potencialmente informativos por um usuário.

Documentos, no entanto, são objetos especiais inseridos em relações sígnicas, por serem artefatos, por serem artificiais, por carregarem uma intencionalidade. Significativamente, no esquema triádico de Pierce, o produtor/criador do signo e sua intencionalidade, não são mencionados. Mesmo em propostas recentes de fundamentos da Ciência da Informação (BRIER, 2004; HUANG, 2006), ao assentar seus fundamentos na Semiótica e Capurro (2003), ao assentar estes fundamentos na Hermenêutica, também não tomam conhecimento do produtor/criador do signo e de sua intencionalidade. A intencionalidade do produtor/criador, no entanto, é básica para caracterizarmos documentos. Um antílope qualquer é informativo para um cientista, mas não é um documento. O antílope, em condições naturais, pressupõe um determinado contexto. O antílope de Briet, ao passar por um processo de patrimonialização, enquanto objeto de interesse da ciência e da cultura, ao qual foi agregado valor informativo ao ser re-contextualizado, quando esta re-contextualização é registrada com a intenção de informar, transforma-se num híbrido objeto cultural-documento. $O$ trabalho intencional de um profissional de informação transforma um objeto em documento.

A intencionalidade, portanto, é fundamental, tanto para a caracterização de objeto potencialmente informativo como para um documento e como para caracterizar o trabalho do profissional de informação. De certa forma, desde que o conhecimento se autonomizou, com o surgimento dos documentos, sempre existiu e cada vez mais existe uma super-oferta de potencialidades informativas. Profissionais de informação e, pode-se dizer, sistemas de informação, trabalham com a intenção de maximizarem as oportunidades de interpretação de objetos com potencial informativo por parte de usuários. Esse potencial informativo é determinado por consenso, a partir da avaliação coletiva deles, como afirma Buckland (1991, p. 9). Para fazerem isso, profissionais de informação criam signos - representações de documentos ou de objetos com potencial informacional - e as organizam de forma sistêmica em dispositivos como catálogos, bases de dados, índices, etc. para viabilizar que usuários encontrem os recursos informacionais de seu interesse de forma otimizada. O trabalho com representações obedece aos mesmos princípios econômicos que o pensamento simbólico e a linguagem: é muito mais vantajoso do ponto de vista de dispêndio de energia trabalhar com representações que lidam diretamente com a realidade; quando consultamos um mapa para nos orientarmos, quando usamos uma planta baixa para avaliarmos espaços num prédio, estamos 
trabalhando com representações e nos valendo da economia de energia proporcionada por elas.

Representações, como uma referência bibliográfica inserida num dispositivo como um catálogo, permitem que usuários decidam confortavelmente sobre a relevância de documentos, com um dispêndio de energia muito menor que se tivessem que consultá-los de maneira aleatória. Referências, enquanto signos de signos, signos de documentos, permitem aos usuários realizarem inferências sobre a relevância dos mesmos com um alto grau de certeza e decidirem se vale a pena despender energia extra para acessá-los, lê-los, estudá-los, etc. Na economia da informação (MARCONDES, 2001) este é o valor que o profissional de informação e sistemas de informação agregam com seus serviços e produtos.

$\mathrm{Na}$ visão apresentada, documentos são entidades sociais vivas, inseridos em redes sociais (FROHMANN, 1995) como um dos seus componentes essenciais, dos quais as sociedades contemporâneas lançam mão e dependem para viabilizarem coordenação, cooperação e articulação social. Cristalizam protocolos e relações sociais de força que os documentos, de alguma maneira, representam.

Podem-se formalizar estas diferentes noções acerca de uma ontologia do documento, analisando-o segundo as seguintes perspectivas analíticas e complementares:

Evolutiva - já discutida na Seção 2.

Objeto sócio-técnico-cultural:

Objeto em si - documentos só podem ser vistos em si com extremo cuidado, enquanto objetos de análise.

Documentos são artefatos sócio-técnicos que se constituem em unidades discretas de registro e transferência mediada de mensagens - conjuntos de signos sistematizados;

Documentos são produzidos a partir da intencionalidade de seu produtor, de transferir signos através do tempo e do espaço.

Enquanto artefato sócio-tecnico, documentos são condicionados tecnologicamente; nesta perspectiva analítica (PÉDAUQUE, 2003) documentos têm suporte, forma, conteúdo, componentes e relações com outros documentos; 
A função sígnica do documento é registrar fatos e atestar, portanto, sua ocorrência. Esta função se desdobra através da intencionalidade do produtor/criador do signo, do seu conteúdo, da sua forma e do contexto social onde o documento funciona, este, essencial para a realização dessa função.

Função instrumental-social - caráter primário:

As funções dos documentos acontecem dentro de contextos sociais bem definidos. Documentos têm um caráter normativo, são instaurados e instauram relações sociais, são instituições sociais, criados para um propósito específico; documentos em seu uso real carregam uma série de pressupostos ontológicos implícitos que são fundamentais para a sua compreensão segundo essa perspectiva;

Documentos pressupõem um protocolo social ao qual eles atendem que se desdobra em três contextos específicos: um contexto de produção/produtor, um contexto de transferência e um contexto de uso/usuário.

Função Cultural, caráter patrimonial - secundário - patrimonialização de objetos culturais, incluso documentos:

Documentos quando reconhecidos pelo seu valor enquanto objetos culturais - uma obra rara numa biblioteca, um documento arquivístico de valor histórico - ou quando agregados a outros objetos, documentando-os e complementando-os enquanto objetos culturais - num híbrido objeto cultural-documento -, como o antílope numa coleção zoológica ou um objeto museológico catalogado.

Nestas situações, documentos, pelo seu valor cultural, pelo seu caráter único ou por serem representativos de um conjunto de outros, sacrificam sua portabilidade.

Relações entre Documentos

Documentos compostos - documentos hipertextuais, "multimídia", compostos de texto, imagens, sons; documentos com partes, como um fascículo de periódico ou anais de um congresso; 
Conjuntos de documentos - fundos, séries, dossiês de arquivos;

Coleções de documentos - coleções em geral, coleções de bibliotecas;

Metadocumentos - documentos que se referem a outros documentos, como tesauros, esquemas de classificação, documentos secundários, terciários: bibliografias/bases de dados, relatórios de estado da arte.

Trabalho informacional

Ao se autonomizar em documentos a cultura e o conhecimento adquiriram novas potencialidades e funções sociais; no entanto, documentos não possuem valor social por si, mas demandam trabalho "informacional" para viabilizar suas funções.

Grande parte deste trabalho informacional que agrega valor aos documentos consiste na atividade de representar.

\section{Conclusões}

Ao revisarmos a trajetória evolutiva da humanidade, verificamos que as funções de articulação, coordenação e cooperação social imediata se sofisticaram e ganharam novas potencialidades com a evolução da linguagem, através da criação de uma memória social não imediata, e daí se sofisticou para a escrita e os documentos. Enquanto fenômenos culturais, entre os diferentes processos informativos, são de especial interesse aqueles que envolvem documentos e a aquisição de conhecimento mediado por documentos. Ao permitir transferir mensagens através do espaço e do tempo, a "invenção" do documento mantém, amplia e potencializa as funções de articulação, coordenação, cooperação e memória social da linguagem. Mensagens externalizadas em documentos tornam-se autônomas do seu criador/produtor, permitem perenizar a ocorrência de fatos, as experiências e conhecimento e, dessa maneira, reutilizá-los.

Documentos são um avanço tecnológico, uma ferramenta que, ao externalizar o conhecimento e autonomizá-lo, permitiu e criou a necessidade social de armazená-lo, preservá-lo, transferi-lo e recuperá-lo, de modo a permitir cotejá-lo, atualizá-lo e re-utilizá-lo. Todas essas operações sociais sobre o conhecimento registrado em documentos constituem o trabalho informacional. Este vem tendo suas potencialidades expandidas com o aporte das tecnologias de informação, permitindo assim 
a apropriação social em larga escala do conhecimento, como é requerido pela sociedade atual.

Enquanto artefato sócio-técnico inserido na Cultura, o documento pressupõe o processo informativo de documentar, enquanto intencionalidade. A materialidade/instrumentalidade do documento só é possível enquanto inserido em relações sociais que o instauram e que são instauradas por ele. Separar essas múltiplas dimensões é ter uma visão parcial e unilateral dos processos sociais envolvendo o documento.

A visão do documento como um artefato sócio-técnico introduz uma dimensão social que é essencial para compreensão do seu papel em nossa sociedade e em sociedades passadas. Um documento, visto como um artefato social se refere implícita e/ou explicitamente a um conjunto de outros documentos e, implicitamente, a um conjunto de relações sociais sem as quais sua compreensão é incompleta. Os diferentes tipos de certificados de propriedade, de escrituras de imóveis, referem-se ou pressupõe, implicitamente, a todo um conjunto de leis que formalizam relações sociais. Artigos científicos aceitos para publicação em periódicos significam pontos no sistema de retribuições vigente na comunidade acadêmica. Documentos de identidade referem-se a registros do cidadão numa instituição da administração pública e também a toda uma legislação.

A proposta histórica da CI pode ser relacionada com o movimento de autonomização do conhecimento iniciado com 0 surgimento de documentos, no que seria um "information approach", a autonomização do conteúdo de documentos no contexto específico de C\&T nas décadas de 60 e 70 do século XX. A chamada "explosão informacional" e a abordagem temática (FOSKETT, 1973) da "informação" coincidem naturalmente e se tornam necessidades sociais, com o fracionamento crescente da Ciência que se verifica desde o início do século XX; neste sentido, "informação" torna-se, pela primeira vez, numa "commodity", adquire valor econômico ao ser reconhecida como insumo direto para o conhecimento e daí para a produção. Os problemas de gestão - teóricos, práticos, tecnológicos - daí decorrentes, são a justificativa social da Ciência da Informação (CI).

Posteriormente, nas décadas de 1980 e 1990, a CI pretendeu estender seu escopo para contextos e domínios mais amplos, aplicando aí bases teóricas apoiadas no mesmo conceito de informação. Como já mencionado, informação é um conceito de grande generalidade e se aplica a uma ampla gama de fenômenos, que interessam a diversas ciências. No entanto, todo uso social de registros da cultura humana é determinado por contextos e domínios muito específicos e todo movimento de generalização deve ser muito cuidadoso para não supervalorizar aspectos que são dependentes de contexto, como a perspectiva temática. Neste sentido, uma teoria do documento, conforme esboçado, é mais ampla e genérica, contemplando variadas perspectivas, inclusive a temática.

O Documento é uma conquista tecnológica da humanidade que permitiu um novo patamar no desenvolvimento da cultura. Como instrumento e extensão da mente e da linguagem humanas, ele permite 
mediar o conhecimento adquirido, superar as fragilidades da memória e transferir conhecimento através do espaço e do tempo. É inquestionável o papel do conhecimento para o desenvolvimento da sociedade atual ou no, nas palavras de Castells (1999, p. 54): "modo informacional de desenvolvimento". No entanto, qualquer que seja o contexto, só o conhecimento fixado, registrado em documentos, permite sua apropriação social em larga escala, como é requerido pela sociedade atual.

A Ciência da Informação evoluiu de visões que consideravam a informação como uma característica física (CLEVERDON; MILL; KEEN, 1966), passando por considerar os processos cognitivos individuais de interpretação como a essência da informação (INGWERSEN, 1996), até uma visão que reconhece estes processos cognitivos individuais como determinados socialmente (HJÖRLAND, 2004). O esquema das diferentes perspectivas do documento previamente delineado é ainda um esboço incompleto a ser desenvolvido. No entanto, uma perspectiva ampla, tendo por base diferentes perspectivas, é capaz de integrar estas visões complementares centradas e, a partir de documentos, enquanto artefatos sócio-técnicos, criados intencionalmente como viabilizadores de processos informativos socialmente mediados.

\section{Referências}

ARTE NOS SÉCULOS. São Paulo: Abril Cultural, s.d. (Da pré-história ao classicismo, v. 1).

BATES, M. J. Information and knowledge: an evolutionary framework for Information Science. Information Research, v. 10, n. 4, July, 2005. Disponível em <http://informationr.net/ir/10-4/paper239.html>. Acesso em: 23 ago. 2005.

BELKIN, N. J.; ROBERTSON, S. E. Information Science and the phenomenon of information. Journal of the American Society for Information Science, p. 197-204, July-August, 1976.

BRIER, S. Cybersemiotics and the problem of information processing paradigm as a candidate for a unified science of information behind library information science. Librar y Trends, v. 52, n. 3, p. 629-658, 2004. Disponível em <http://www.periodicos.capes.gov.br>. Acesso em: 1 ago. 2004.

BRIET, S. What is documentation? MD: Scarecrow Press, 2006. Disponível em <http://people.ischool.berkeley.edu/ buckland/briet.html>. Acesso em: 24 jul. 2009.

BROOKES, B. C. The foundations of information science. Part I: Philosophical aspects. Journal of Information Science, v. 2, n. 3-4, p. 125133, $1980 . \quad$ Disponível em: $<$ http://comminfo.rutgers.edu/ kantor/601/Readings2004/Week3/r4.PDF $>$. Acesso em: 24 jul. 2009. 
The foundations of information science. Part II: Quantitative aspects: classes of things and the challenge of human individuality. Journal of Information Science, v. 2, n. 5, p. 209 - 221, 1980.

BROWN, J. S.; DUNGUID, P. The social life of documents. First Monday, v. 1, n. 6, May 1996. Disponível em: <http://firstmonday.org/htbin/cgiwrap/bin/ojs/index.php/fm/article/view/ 466/820 >. Acesso em: 05 mar. 2009.

BUCKLAND, M. Information as thing. Journal of the American Society of Information Science, v. 42, n. 5, p. 351-360, 1991. Disponível em: <http://www.sims.berkley.edu/ buckland/thing.html>. Acesso em: 9 nov. 2003.

BÜHLER, K. Theory of language: the representational function of language. Philadelphia/Amsterdam: John Benjamin Publishing Company, 1990.

CAPURRO, R. Epistemologia e Ciência da Informação. In: ENCONTRO NACIONAL DE PESQUISA E PÓS-GRADUAÇÃO EM CIÊNCIA DA INFORMAÇÃO (ENANCIB), 5., Belo Horizonte, Anais... Belo Horizonte: ECI/UFMG, 2003.

CASTELLS, M. A sociedade em rede: a era da informação: economia, sociedade e cultura. São Paulo: Paz e Terra, 1999. v. 1.

PIERCE, C. S. Collected Papers. Cambridge: Harvard University Press, 1958 apud SANTAELLA, L.; VIEIRA, J. A. Metaciência: como guia da pesquisa. São Paulo: Ed. Mérito, 2008.

CHOMSKY, N. Syntactic structures. 2. ed. Berlin, New York: Mouton de Gruyter, 2002.

CLEVERDON, C. W.; MILL, J.; KEEN, E. M. Factors determining the performance of indexing systems. Cranfield, UK: Aslib Cranfield Research Project, College of Aeronautics, 1966. (Volume 1:Design; Volume 2: Results).

DUNBAR, R. I. M. Coevolution of neocortical size, group size and language in humans. Behavioral and Brain Sciences, v. 16, n. 4, p. 681-735, 1993. Disponível

$<$ http://www.bbsonline.org/documents/a/00/00/05/65/bbs00000565-

00/bbs.dunbar.html?rel=nofollow >. Acesso em: 14 jul. 2009.

ENARD, W. et al. Molecular evolution of FOXP2, a gene involved in speech and language. Nature, v. 418, 22 August 2002. Disponível em <http://www.periodicos.capes.gov.br>. Acesso em: 22 nov. 2009.

FOSKETT, A. C. A abordagem temática da informação. São Paulo: Polígono; Brasília: Editora da UNB, 1973.

FREITAS, L. S. Sentidos da história e história dos sentidos da Ciência da Informação. Morpheus, n. 2, 2003. Disponível em: <http://www.unirio.br/morpheusonline/Numero02-2003/lidiafreitas.htm>. Acesso em: 20 jul. 2009. 
FROHMANN, B. O caráter social, material e público da informação na contemporaneidade. In: ENCONTRO NACIONAL DE PESQUISA E PÓSGRADUAÇÃO EM CIÊNCIA DA INFORMAÇÃO (ENANCIB), 7., Marília, Anais... Marília: [s.n.], 2006.

Taking policy beyond information science: applying the actor network theory for connectedness: information, systems, people, organizations. In: ANNUAL CONFERENCE OF CANADIAN ASSOCIATION FOR INFORMATION SCIENCE, 23., 1995, Proceedings... Edmond, Alberta, 1995. Disponível em: <http://instruct.uwo.ca/faculty/Frohmann>. Acesso em: 1 out. 2008.

HJÖRLAND, B. Domain analysis: a socio-cognitive orientation for Information Science research. Bulletin of the American Society for Information Science and Technology, feb/mar. 2004. Disponível em $<$ http://www.asis.org/Bulletin/Feb-04/hjorland.html>. Acesso em: 23 mar. 2009.

HUANG, S. A Semiotic View of Information: Semiotics as a Foundation of LIS Research in Information Behavior. In: ANNUAL MEETING OF THE AMERICAN SOCIETY FOR INFORMATION SCIENCE AND TECHNOLOGY (ASIST), 43., Proceedings... Austin (US), 2006. Disponível em $<$ http://eprints.rclis.org/archive/00008436/01/Huang Semiotic.pdf $>$.

Acesso em: 4 nov. 2008.

INGWERSEN, $P$. Cognitive perspectives of information retrieval interaction: elements of a cognitive IR theory. Journal of Documentation, v. 52, n. 1, p. 3-50, March 1996.

KNIGHT, C. et al. Language: a Darwinian adaptation? In: KNIGHT, C.; STUDDERT-KENNEDY, M.; HURFORD, J. R. (Eds.). The evolutionary emergence of language: social functions and the origins of linguistic form. Cambridge: Cambridge University Press, 2000. Disponível em $<$ http://catdir.loc.gov/catdir/samples/cam031/00020471.pdf>. Acesso em: 13 fev. 2009.

LE GOFF, J. Documento/Monumento. In: HISTÓRIA e Memória. Campinas: Ed. Unicamp, 2003. p. 525-541.

LUND, N. W. Document theory. In: ANNUAL REVIEW OF INFORMATION SCIENCE AND TECHNOLOGY, Silver Spring, MD, EUA: ASIS\&T; Meford, NJ, EUA: Information Today, 2009. p. 399-432.

MAARTENS, W. The basic elements of nature: matter, energy, and information. [S.I.]: Authorsden.com, 2007. Disponível em $<$ http://www.authorsden.com/visit/viewarticle.asp?id=30331>. Acesso em: 15 jan. 2010.

MARCONDES, C. H. Representação e economia da informação. Ciência da Informação, v. 30, n. 1, p.61-70, 2001. Disponível em $<$ http://www.scielo.br/scielo.php?script=sci arttext\&pid=S010019652001000100008\&lng=en\&nrm=iso >. Acesso em: 15 jan. 2010. 
MATURANA, H. R.; VARELA, F. J. A árvore do conhecimento: as bases biológicas da compreensão humana. São Paulo: Palas Athena, 2001.

NOWAK, M.; KOMAROVA, N. L. Towards an evolutionary theory of language. TRENDS in Cognitive Sciences, v. 5, n. 7, p.288-295, 2001.

ONLINE Ethimology Dictionary. Disponível em

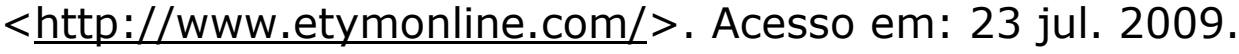

PÉDAUQUE, R. Document: form, sign and medium, as reformulated for electronic documents. [S.I.: s. n.] 2003. Disponível em: <http://archivesic.ccsd.cnrs.fr/docs/00/06/22/28/HTML/index. html>. Acesso em: 30 out. 2003.

PLATÃO. Fedro. São Paulo: Martin Claret, 2007. (A Obra-prima de cada autor).

POPPER, K. Em busca de um mundo melhor. Lisboa: Fragmentos, 1992.

. El cuerpo y la mente. Barcelona: Paidós, 1997.

RABER, D.; BUDD, J. M. Information as sign: semiotics and information Science. Journal of Documentation, v. 59, n. 5, p.507-522, 2003. Disponível em <http://www.periodicos.capes.gov.br>. Acesso em: 15 ago. 2004.

ROUSSEU, J.; COUTURE, C. Os fundamentos da disciplina arquivística. Lisboa: Dom Quixote, 1998.

SHERA, J. H.; CLEVELAND, D. B. History and foundations of Information Science. Annual Review of Information Science and Technology, v. 12, p. 249-275, 1977.

SMITH, B. Document acts. [S.I.],[2005]. Disponível em: <http://ontology.buffalo.edu/document ontology/document acts.doc $>$.

Acesso em: 20 mar. 2007.

TATTERSALL, Y. Como nos tornamos humanos. Scientific American Brasil, edição especial, n. 17, p. 69-75, [2007?].

VYGOTSKY, L. S. Pensamento e linguagem. [S.I.]: Ebooks.com, 2001. Disponível em: <http://www.ebooksbrasil.org/adobeebook/vigo.pdf>. Acesso: 11 jul. 2009.

WONG, K. O despertar da mente humana. Scientific American Brasil Edição especial n. 17, p. 76-83, [2007?].

ZINS, C. Conceptual Approaches for Defining Data, Information, and Knowledge. Journal of the American Society for Information Science and Technology, v. 58, n. 4, p. 479-493, 2006, 